\section{Bandshift assays.}

Standard bandshift reactions (Fig. 3a) utilized ${ }^{32} \mathrm{P}$-labelled 'BH' probes that contained three CpG sites (underlined below) whose methylation/mismatch status was varied. The $\mathrm{BH}$ probes used in Fig. 3c were

\section{5'TCAGATTCGCGCZGGCTGCGATAAGCTGZZGCGGATCCZZGGGAATTCAGCT3'}

\section{3'AGTCTAAGCGCGGYCGACGCTATTCGACGYGCCTAGGGYCCTTAAGTCGA5'}

where $\mathrm{Y}=\mathrm{C}, \mathrm{m}^{5} \mathrm{C}$, T or $\mathrm{U}$, and $\mathrm{Z}=\mathrm{C}$ or $\mathrm{m}^{5} \mathrm{C}$ (see underlined dinucleotides). The three $\mathrm{CpG}$ sites were identically modified/mismatched within each probe. Binding reactions were carried out at room temperature for $30 \mathrm{~min}$ in $20 \mathrm{mM}$ HEPES pH 7.9, $25 \mathrm{mM} \mathrm{NaCl}$, $10 \mathrm{mM} \beta$-mercaptoethanol, $1 \mathrm{mM}$ EDTA, $4 \%$ glycerol, $1 \%$ digitonin and $50 \mathrm{ng}$ sonicated E. coli DNA. The glycosylase reaction does not occur under these conditions (data not shown). Complexes were electrophoresed through $6 \%$ polyacrylamide gels in $0.5 \times \mathrm{TBE}$ at $4{ }^{\circ} \mathrm{C}$.

Complexes formed under conditions favourable to the glycosylase reaction (Fig. 3b, c) utilized the fluorescent or ${ }^{32} \mathrm{P}$-labelled JJ oligonucleotide (see above) as a probe. In standard gel-retardation reactions, $200 \mathrm{nM}$ protein was incubated with $66 \mathrm{nM}$ labelled oligonucleotide substrate and $333 \mathrm{nM}$ unlabelled homoduplex oligonucleotide in $50 \mathrm{mM}$ Tris- $\mathrm{HCl} \mathrm{pH} \mathrm{8.0,} 1 \mathrm{mM}$ DTT, $5 \%$ glycerol, $1 \mathrm{mM}$ EDTA at $37^{\circ} \mathrm{C}$ for $20 \mathrm{~min}$. The samples were electrophoresed immediately through a $6 \%$ native $0.5 \times$ TBE polyacrylamide gel for $45 \mathrm{~min}$ at $100 \mathrm{~V}$. A probe with an abasic site was generated by treatment of oligonucleotide JJ containing a MG.UG mismatch with the enzyme uracil DNA glycosylase.

Received 25 June; accepted 21 July 1999

1. Duncan, B. K. \& Miller, J. H. Mutagenic deamination of cytosine residues in DNA. Nature 287, 560 561 (1980).

2. Britten, R. J., Baron, W. F., Stout, D. B. \& Davidson, E. H. Sources and evolution of human Alu repeated sequences. Proc. Natl Acad. Sci. USA 85, 4770-4774 (1988).

3. Sved, J. \& Bird, A. The expected equilibrium of the $\mathrm{CpG}$ dinucleotide in vertebrate genomes under a mutation model. Proc. Natl Acad. Sci. USA 87, 4692-4696 (1990).

4. Bulmer, M. Neighboring base effects on substitution rates in pseudogenes. Mol. Biol. Evol. 3, 322-329 (1986).

5. Bird, A. P. DNA methylation and the frequency of CpG in animal DNA. Nucleic Acids Res. 8, 1499 1594 (1980).

6. Cooper, D. N. \& Youssoufian, H. The CpG dinucleotide and human genetic disease. Hum. Genet. 78 , 151-15 (1988)

7. Hollstein, M. et al. Database of p53 gene somatic mutations in human tumors and cell lines. Nucleic Acids Res. 22, 3551-3555 (1994)

8. Jones, P. A., Rideout, W. M., Shen, J.-C., Spruck, C. H. \& Tsai, Y. C. Methylation, mutation and cancer BioEssays 14, 33-36 (1992)

9. Lindahl, T. An N-glycosidase from Escherichia coli that releases free uracil from DNA containing deaminated cytosine residues. Proc. Natl Acad. Sci. USA 71, 3649-3653 (1974).

10. Lindahl, T., Karran, P. \& Wood, R. D. DNA excision repair pathways. Curr. Opin. Genet. Dev. 7, 158 169 (1997).

11. Wiebauer, K. \& Jiricny, J. In vitro correction of G.T mispairs to G.C pairs in nuclear extracts from human cells. Nature 339, 234-236 (1989).

12. Neddermann, P. et al. Cloning and expression of human G/T mismatch-specific thymine-DNA glycosylase. J. Biol. Chem. 271, 12767-12774 (1996).

13. Nan, X., Meehan, R. R. \& Bird, A. Dissection of the methyl-CpG binding domain from the chromosomal protein MeCP2. Nucleic Acids Res. 21, 4886-4892 (1993).

14. Hendrich, B. \& Bird, A. Identification and characterization of a family of mammalian methyl-CpG binding proteins. Mol. Cell. Biol. 18, 6538-6547 (1998).

15. Nan, X., Campoy, J. \& Bird, A. MeCP2 is a transcriptional repressor with abundant binding sites in genomic chromatin. Cell 88, 471-481 (1997)

16. Michaels, M. L., Pham, L., Nghiem, M., Cruz, C. \& Miller, J. H. MutY, an adenine glycosylase active on G-A mispairs, has homology to endonuclease III. Nucleic Acids Res. 18, 3841-3845 (1990).

17. Horst, J. P. \& Fritz, H. J. Counteracting the mutagenic effect of hydrolytic deamination of DNA 5-methylcytosine residues at high temperature: DNA mismatch N-glycosylase Mig.Mth of the thermophilic archaeon Methanobacterium thermoactotrophicum THF. EMBO J. 15, 5459-5469 (1996).

18. Asahara, H., Wistort, P. M., Bank, J. F., Bakerian, R. H. \& Cunningham, R. P. Purification and characterization of Escherichia coli endonuclease III from the cloned nth gene. Biochemistry 28, 4444449 (1989).

19. Shiota, S. \& Nakayama, H. UV endonuclease of Micrococcus luteus, a cyclobutane pyrimidine dimerDNA glycosylase/abasic lyase: cloning and characterization of the gene. Proc. Natl Acad. Sci. USA 94, 593-598 (1997).

20. Robson, C. N. \& Hickson, I. D. Isolation of cDNA clones encoding a human apurinic/apyrimidinic endonuclease that corrects DNA repair and mutagenesis defects in E. coli xth (exonuclease III) mutants. Nucleic Acids Res. 19, 5519-5523 (1991)

21. Scharer, O. D., Nash, H. M., Jiricny, J., Laval, J. \& Verdine, G. L. Specific binding of a designed pyrrolidine abasic site analog to multiple DNA glycosylases. J. Biol. Chem. 273, 8592-8597 (1998).

22. Gallinari, P. \& Jiricny, J. A new class of uracil-DNA glycosylases related to human thymine-DNA glycosylase. Nature 383, 735-738 (1996).

23. Sibghat-Ullah et al. Base analog and neighboring base effects on substrate specificity of recombinant human G:T mismatch-specific thymine DNA glycosylase. Biochemistry 35, 12926-12932 (1996).

24. Bellacosa, A. et al. MED1, a novel human methyl-CpG-binding endonuclease, interacts with DNA mismatch repair protein MLH1. Proc. Natl Acad. Sci. USA 96, 3969-3974 (1999).

25. Modrich, P. \& Lahue, R. Mismatch repair in replication fidelity, genetic recombination and cancer biology. Аnпu. Rev. Biochem. 65, 101-133 (1996).

26. Jiricny, J. Replication errors: cha(lle)nging the genome. EMBO J. 17, 6427-6436 (1998).

27. Maniatis, T., Fritsch, E. F. \& Sambrook, J. Molecular Cloning: A Laboratory Manual 196-198 (Cold Spring Harbor, New York, 1982).

\section{Acknowledgements}

We thank P. Hunziger for HPLC analysis; P. Schär, R. Wood and T. Lindahl for fruitful discussions; I. Hickson for the HAP1 endonuclease; and S. Tweedie for comments on the manuscript. This work was supported by grants from the Wellcome Trust (B.H. and A.B.), the Schweizerische Krebsliga (U.H. and J.J.) and by a Darwin Trust Scholarship to H-H.N.

Correspondence and requests for materials should be addressed to A.B. (e-mail: A.Bird@ed.ac.uk).

\section{erratum}

\section{Full sintering of powdered-metal bodies in a microwave field}

\section{Rustum Roy, Dinesh Agrawal, Jiping Cheng \& Shalva Gedevanishvili}

Nature 399, 668-670 (1999)

In the penultimate paragraph of this Letter, there are two instances where "electric field" has been used when "magnetic field" is meant: one is in the fourth sentence and the other in the last. 
well known average velocity $\left(v=0.89 \mathrm{nms}^{-1}\right)$ and orientation. Taking the derivative of these trajectories yields a plot of the longitudinal velocities versus time (Fig. 2b). For clarity, we shifted the results for vortex $\mathrm{A}$ and $\mathrm{C}$ by $\pm 1 \mathrm{~nm} \mathrm{~s}^{-1}$. The error bar denotes the uncertainty in $v\left(\delta v= \pm 0.15 \mathrm{~nm} \mathrm{~s}^{-1}\right)$ due to the error in the vortex positions. The horizontal bar marks the time needed to traverse a distance $10 a_{0}(630 \mathrm{~nm})$. It is clearly seen that the velocity is modulated with a periodic component with amplitude $\Delta v \approx$ $0.6 \mathrm{~nm} \mathrm{~s}^{-1}$ and period $a_{0} / v$. In the Fourier transform (Fig. 2c), this shows up as a peak at $14.1 \mathrm{mHz}$. Such a peak at the "washboard" frequency is known for periodic structures driven through random point disorder ${ }^{9}$, but to the best of our knowledge this is the first time that this washboard feature has been found to survive in the creep regime. The periodic modulation also appears in the longitudinal displacement determined with respect to the average, uniform motion versus time. However, it is not observed in a plot of the transverse displacements versus time. Rather, we see on our timescale a random-walk-like transverse excursion of the bundle up to an amplitude $0.2 a_{0}$, not yet enough to decide how the mean-squared displacement grows with time. We leave this for future investigations.

Fast imaging of vortex lattices by STM provides the possibility of studying the collective and plastic flow behaviour of elastic media through various configurations of disorder.

Received 7 December 1998; accepted 5 April 1999.

1. Blatter, G. et al. Vortices in high-temperature superconductors. Rev. Mod. Phys. 66, 1125-1388 (1994)

2. Koshelev, A. E. \& Vinokur, V. M. Dynamic melting of the vortex lattice. Phys. Rev. Lett. 73, 3580-3583 (1994).

3. Giamarchi, T. \& LeDoussal, P. Moving glass phase of driven lattices. Phys. Rev. Lett. 76, 3408-3411 (1996).

4. Le Doussal, P. \& Giamarchi, T. Moving glass theory of driven lattices with disorder. Phys. Rev. B 57, $11356-11403(1998)$

5. Moon, K., Scalettar, R. \& Zimámny, G. T. Dynamical phases of driven vortex systems. Phys. Rev. Lett. 77, 2778-2781 (1996)

6. Scheidl, S. \& Vinokur, V. M. Driven dynamics of periodic elastic media in disorder. Phys. Rev. B 57, 13800-13810 (1998).

7. Balents, L., Marchetti, M. C. \& Radzikovsky, L. Nonequilibrium steady states of driven periodic media. Phys. Rev. B 57, 7705-7739 (1998).

8. Nattermann, T. Scaling approach to pinning; Charge-density waves and giant flux creep in superconductors. Phys. Rev. Lett. 64, 2454-2457 (1990).

9. Olsen, C. J., Reichhardt, C. \& Nori, F. Nonequilibrium dynamics phase diagram for vortex lattices. Phys. Rev. Lett. 81, 3757-3760 (1998).

10. Osakabe, N., Kasai, H., Kodama, T. \& Tonomura, A. Time-resolved analysis in transmission electron microscopy and its application to the study of the dynamics of vortices. Phys. Rev. Lett. 78, 1711-1714 (1997).

11. Kirtley, J. R. et al. Direct imaging of integer and half-integer Josephson vortices in high- $T_{\mathrm{c}}$ grain boundaries. Phys. Rev. Lett. 76, 1336-1339 (1996).

12. Oral, A. et al. Direct observation of melting of the vortex solid in $\mathrm{Bi}_{2} \mathrm{Sr}_{2} \mathrm{CaCu}_{2} \mathrm{O}_{8+\delta}$ single crystals. Phys. Rev. Lett. 80, 3610-3613 (1998).

13. Mozer, A. et al. Observation of single vortices condensed into a vortex-glass phase by magnetic force microscopy. Phys. Rev. Lett. 74, 1847-1850 (1995).

14. Bolle, C. A., de la Cruz, F., Gammel, P. L., Waszczak, J. V. \& Bishop, D. J. Observation of tilt induced orientational order in the magnetic flux lattice $2 \mathrm{H}-\mathrm{NbSe}_{2}$. Phys. Rev. Lett. 71, 4039-4042 (1993).

15. Yao, Z. et al. Path of magnetic flux lines through high- $T_{\mathrm{c}}$ copper oxide superconductors. Nature 371, 777-779 (1994).

16. Marchevsky, M. V., Aarts, J., Kes, P. H. \& Indenbom, M. V. Observation of the correlated vortex flow in $\mathrm{NbSe}_{2}$. Phys. Rev. Lett. 78, 531-534 (1997).

17. Pardo, F. et al. Real space images of the vortex lattice structure in a Type II superconductor during creep over a barrier. Phys. Rev. Lett. 79, 1369-1372 (1997).

18. Hess, H. F., Robinson, R. B. \& Waszczak, J. V. Vortex-core structure observed with a scanning tunneling microscope. Phys. Rev. Lett. 64, 2711-2714 (1990).

19. Maggio-Aprile, I., Renner, Ch., Erb, A., Walker, E. \& Fischer, Ø. Direct vortex lattice imaging and tunneling spectroscopy of flux lines on $\mathrm{Yba}_{2} \mathrm{Cu}_{3} \mathrm{O}_{7-\delta}$. Phys. Rev. Lett. 75, 2754-2757 (1995).

20. Renner, Ch., Revaz, B., Kadowaki, K., Maggio-Aprile, I. \& Fischer, Ø. Observation of the low temperature pseudogap in the vortex cores of $\mathrm{Bi}_{2} \mathrm{Sr}_{2} \mathrm{CaCu}_{2} \mathrm{O}_{8+\delta}$. Phys. Rev. Lett. 80, 3606-3609 (1998).

21. De Wilde, Y. et al. Scanning tunneling microscopy observation of a square Abrikosov lattice in $\mathrm{LuNi}_{2} \mathrm{~B}_{2}$ C. Phys. Rev. Lett. 78, 4273-4276 (1997).

22. Volodin, A. P., Golubov, A. A. \& Aarts, J. Vortex core shapes measured by STM. Z. Phys. B 102, 317 321 (1997).

23. Volodin, A. P. \& Troyanovski, A. M. A three-phase piezoinertio motor for a low temperature STM Instr. Exp. Techn. 40, 724-726 (1997).

24. Wengel, C. \& Tauber, U. C. Weakly pinned Bose glass vs Mott insulator phase in superconductors. Phys. Rev. Lett. 78, 4845-4848 (1997).

25. Behler, S. et al. Vortex pinning in ion-irradiated $\mathrm{NbSe}_{2}$ studied by scanning tunneling microscopy Phys. Rv. Lett. 72, 1750-1753 (1994).

26. van der Beek, C. J., Nieuwenhuys, G. J. \& Kes, P. H. Nonlinear current diffusion in type-Il superconductors. Physica C 197, 320-336 (1992).

27. Larkin, A. I. \& Ovchinnikov, Yu. N. Pinning in type II superconductors. J. Low Temp. Phys. 34, 409 427 (1979).

28. Angurel, L. A., Amin, F., Polichetti, M., Aarts, J. \& Kes, P. H. Dimensionality of collective pinning in $2 \mathrm{H}$-NbSe, single crystals. Phys. Rev. B 56, 3425-3432 (1997).

29. Schmid, A. \& Hauger, W. On the theory of vortex motion in an inhomogeneous superconducting film. J. Low Temp. Phys. 11, 667-685 (1973).
30. Bauer, P et al. Depth sensitive visualisation of irradiation-induced columnar defects in $2 \mathrm{H}-\mathrm{NbSE}$ Euro. Phys. Lett. 23, 585-591 (1993).

Supplementary information is available on Nature's World-Wide Web site (http://www.nature.com)

Acknowledgements. We thank A. P. Volodin for developing the first version of our STM, R. J. Drost for auxiliary experiments, M. Konczykowski for carrying out the heavy ion irradiation at GANIL (Caen, France), and M. V. Marchevsky, P. Le Doussal and T. Giamarchi for discussions. This project was partially supported by FOM and the Dutch-Russian Science Collaboration financed by NWO.

\section{Full sintering of powdered-metal bodies in a microwave field}

\section{Rustum Roy, Dinesh Agrawal, Jiping Cheng \& Shalva Gedevanishvili}

Materials Research Laboratory, The Pennsylvania State University, University Park, Pennsylvania 16802, USA

The use of microwaves to process absorbing materials was studied intensively in the 1970s and 1980s, and has now been applied to a wide variety of materials ${ }^{1-4}$. Initially, success in microwave heating and sintering was confined mainly to oxide and some nonoxide ceramics ${ }^{5-11}$; but recently the technique has been extended to carbide semimetals ${ }^{12-14}$ used in cutting tools. Here we describe the microwave sintering of powdered metals to full density. We are able to sinter a wide range of standard powdered metals from commercial sources using a $2.45-\mathrm{GHz}$ microwave field, yielding dense products with better mechanical properties than those obtained by conventional heating. These findings are surprising in view of the reflectivity of bulk metals at microwave frequencies. The ability to sinter metals with microwaves should assist in the preparation of high-performance metal parts needed in many industries, for example, in the automotive industry.

Reviews of microwave processing ${ }^{1-5}$ describe its use for materials ranging from wood, bacon and potato chips to rubber, ceramics and semiconductors, but make no mention of metal sintering. Walkiewicz et al. ${ }^{15}$ exposed a range of materials, including six metals (presumably partly oxidized in air) to a $2.4-\mathrm{GHz}$ field, and reported modest heating (but not sintering), ranging from $120^{\circ} \mathrm{C}$ for $\mathrm{Mg}$ to $768^{\circ} \mathrm{C}$ for Fe. Sintering of tungsten carbide-cobalt composites has also been reported ${ }^{16}$. Nishitani reported ${ }^{17}$ that by adding a few per cent of electrically conducting powders such as aluminium, the heating rates of refractory ceramics was considerably enhanced; but no mention was made of the microwave sintering of pure metal powders. Whittaker and Mingos ${ }^{18}$ used the highly exothermic (and rapid) reactions of metal powders with sulphur for the microwaveinduced synthesis of metal sulphides. German ${ }^{19}$ discusses microwave heating of oxide and non-oxide ceramics, but does not mention sintering of metals.

We have used commercial powdered metal components of various alloy compositions-including iron and steel, copper, aluminium, nickel, molybdenum, cobalt, tungsten, tungsten carbide and tin, and their alloys ${ }^{20}$ - to obtain essentially fully dense bodies with substantially improved mechanical properties compared to similar bodies sintered by conventional thermal means. Some of these samples were obtained from Keystone Powdered Metal Company (St. Mary, Pennsylvania, USA) and some were made in our laboratory. They were all standard 'green' parts-metal powders cold-pressed with a few per cent of organic binder. The typical size range was $2-5 \mathrm{~cm}$ in the largest dimension, with a wide variety of rectangular and cylindrical cross-sections, including typical toothed gears in the $1-4-\mathrm{cm}$ range.

Over the past decade we have developed several specialized 
microwave sintering chambers capable of processing a variety of samples with different shapes and sizes, and maintaining any temperature in the range from room temperature to $2,000^{\circ} \mathrm{C}$. The microwave generators are operated at a frequency of $2.45 \mathrm{GHz}$, with power output in the range $1-6 \mathrm{~kW}$, in both single- and multi-mode operation. Inside a typical microwave cavity is an alumina tube surrounded by ceramic fibre (typically mullite) insulation. The primary function of insulation is to preserve the heat inside the tube. Insulation does not absorb microwaves in the lower temperature ranges, but at higher temperatures there is some partition of the power dissipation between the insulation and the sample. For higher temperatures (above $\sim 1,400^{\circ} \mathrm{C}$ ) we use $\mathrm{ZrO}_{2}$ and even $\mathrm{Y}_{2} \mathrm{O}_{3}$ insulation, but these are much more expensive, and the partition is of course different. For some runs we utilize a secondary coupler or microwave susceptor rods made of $\mathrm{SiC}$ or $\mathrm{MoSi}_{2}$. Temperatures are read by optical pyrometers and/or sheathed thermocouples placed very close to the surface of the sample. Although relative readings are accurate to $\pm 5^{\circ} \mathrm{C}$, the absolute temperature has not been established to anywhere near that precision. The atmosphere can be controlled as needed: from air, to $\mathrm{H}_{2}$, to forming gas, to oxygen. A diagram of a typical microwave system for sintering of powdered metals is shown in Fig. 1.

The 'green' commercial powdered-metal bodies are introduced into the microwave chamber and heated at $1,100-1,300^{\circ} \mathrm{C}$ typically for times ranging from 5 minutes to one hour in flowing forming gas $\left(\mathrm{N}_{2}+\mathrm{H}_{2}\right)$ or in a pure hydrogen atmosphere. In a large number of cases, similar samples have been heated in conventional furnaces for direct comparison of the properties. The first few runs produced highly sintered bodies in a very short period of time. This was achieved in our controlled-atmosphere microwave system with $2.45-\mathrm{GHz}$ frequency and a maximum $6-\mathrm{kW}$ power: but only $1.4 \mathrm{~kW}$ of power was used to attain the desired sintering temperatures. Typically the total cycle time was $\sim 90$ minutes. For this sintering process, we have established that similar heating occurs without using susceptors. The only difference is that with susceptors the overall heating is faster. This was proved by conducting several

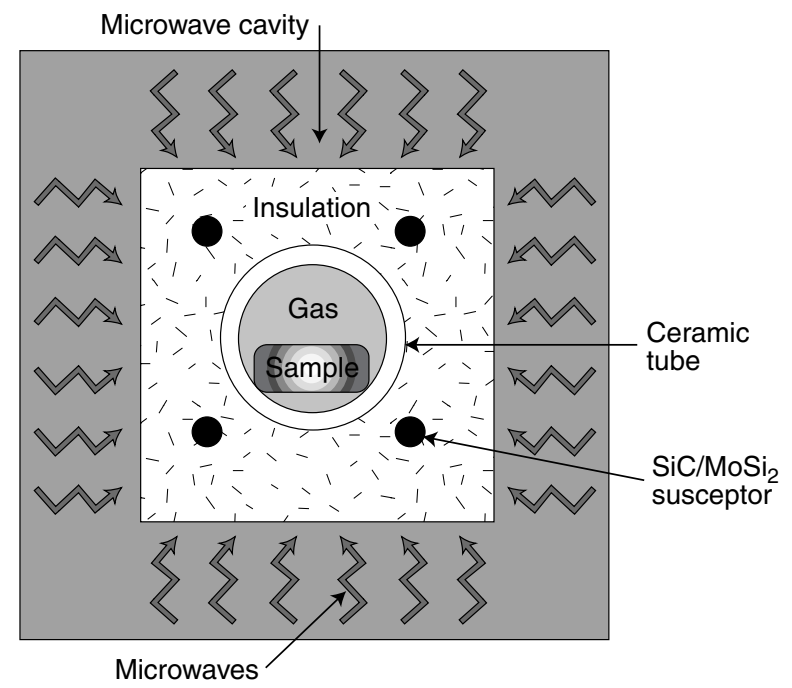

Figure 1 Diagram of microwave system for sintering of powdered-metal parts. The system consists of a $2.54-\mathrm{GHz}$ microwave oven (cavity) and a ceramic (alumina) tube which is inserted into the cavity and surrounded by ceramic fibre blocks. Inside the insulation, $\mathrm{SiC}$ or $\mathrm{MoSi}_{2}$ susceptor rods are inserted. The sample is placed inside the ceramic tube. The system is capable of achieving temperatures up to $1,600^{\circ} \mathrm{C}$, and any desired atmospheres (such as $\mathrm{H}_{2}, \mathrm{~N}_{2}, \mathrm{Ar}$ ) can be used. The same system has been used with or without the susceptor ( $\mathrm{SiC} /$ $\mathrm{MoSi}_{2}$ ) rods; sintering times without the rods are somewhat longer but no other change is noted.
Table 1 Properties of microwave and conventionally processed powderedmetal samples

\begin{tabular}{|c|c|c|c|c|c|}
\hline Sample & Process & $\begin{array}{c}\text { Green } \\
\text { density } \\
\left(\mathrm{g} \mathrm{cm}^{-3}\right)\end{array}$ & $\begin{array}{l}\text { Sintered } \\
\text { density } \\
\left(\mathrm{g} \mathrm{cm}^{-3}\right)\end{array}$ & $\begin{array}{l}\text { Rockwell } \\
\text { hardness }\end{array}$ & $\begin{array}{c}\mathrm{MOR} \\
\left(10^{3} \mathrm{Ib} \mathrm{in}^{-2}\right)\end{array}$ \\
\hline $\begin{array}{l}\mathrm{Fe}-\mathrm{Ni} \\
\text { (industrial part) }\end{array}$ & $\begin{array}{l}\text { MW } \\
\text { Conv. }\end{array}$ & 7.11 & $\begin{array}{l}7.15 \\
7.10\end{array}$ & $\begin{array}{l}\text { B82 } \\
\text { B77 }\end{array}$ & $\begin{array}{l}177 \\
109\end{array}$ \\
\hline $\begin{array}{l}\mathrm{Fe}-\mathrm{Cu} \\
\text { (industrial part) }\end{array}$ & $\begin{array}{l}\text { MW } \\
\text { Conv. }\end{array}$ & 6.81 & $\begin{array}{l}7.17 \\
6.84\end{array}$ & $\begin{array}{l}\text { B96 } \\
\text { B80 }\end{array}$ & $\begin{array}{l}142 \\
118\end{array}$ \\
\hline $\begin{array}{l}\text { Fe-Cu } \\
\text { (lab. sample) }\end{array}$ & $\begin{array}{l}\text { MW } \\
\text { Conv. }\end{array}$ & 6.95 & $\begin{array}{l}6.96 \\
6.95\end{array}$ & $\begin{array}{l}\text { B75 } \\
\text { B64 }\end{array}$ & $\begin{array}{l}134 \\
122\end{array}$ \\
\hline
\end{tabular}

MW, microwave processed; conv., conventionally processed. The modulus of rupture (MOR) of most microwave-processed samples is higher than that of the conventional samples. The densities of many microwave-processed samples are also higher than those of conventional samples.

experiments by removing the susceptors altogether and monitoring the power level. It was also established in essentially all cases that the net shape of the green part was retained precisely (with the usual shrinkage if any was planned), and a fine microsctructure was produced.

Table 1 shows data for some of these microwave-processed parts, and the corresponding properties of parts of the same composition made by conventional means. Our findings indicate that every powdered-metal 'green' body so far tested could be sintered in 10-30 minutes in an appropriate microwave sintering apparatus. It is also clear that in almost all cases, the modulus of rupture (MOR) of microwave-processed samples is substantially higher than the conventional samples; in the case of the $\mathrm{Fe}-\mathrm{Ni}$ composition, it was $60 \%$ higher. The densities of many microwave-processed samples are also higher than conventional samples.

The samples with a composition of $\mathrm{Fe}+\mathrm{Cu}(2 \%)+$ graphite $(0.8 \%)$ were processed in a microwave field at $1,200{ }^{\circ} \mathrm{C}$ for 30 minutes. The microwave-sintered and 'green' samples were characterized for their microstructure by optical microscopy and for phase composition by X-ray diffractrometry. The microstructure

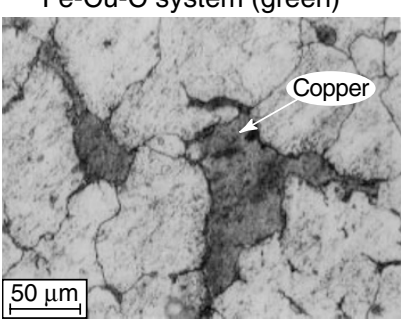

c

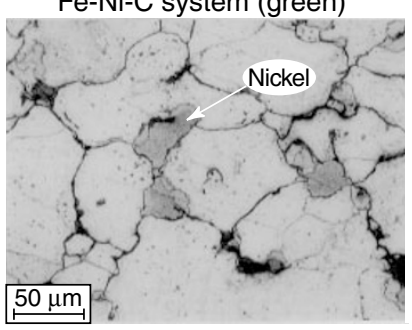

b

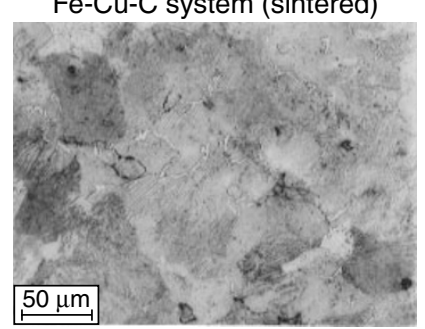

d Fe-Ni-C system (sintered)
Figure 2 Optical micrographs of two sets of 'green' (that is, unsintered) and microwave-sintered powdered-metal parts processed at $1,200^{\circ} \mathrm{C}$ for 30 minutes. a, b, Fe-Cu-C; 'green' sample (a), microwave-sintered sample (b). c, d, Fe-Ni-C; 'green' sample (c), microwave-sintered sample (d). Microwave-sintered powdered-metal parts show excellent sintering of Fe particles. In the Fe-Cu-C system, copper melted and spread into Fe particle boundaries forming Fe-Cu solid solutions (b). In the Fe-Ni-C system, the microstructure shows light shades for austenitic nickel-rich islands (d). In both cases, the formation of steel was confirmed by $\mathrm{X}$-ray diffraction. 
photographs (Fig. 2) indicate that excellent sintering had occurred between the iron particles, and that the copper had melted and spread into the iron-particle boundaries forming $\mathrm{Fe}-\mathrm{Cu}$ solid solutions. The X-ray diffractograms confirm the microscopy observations, and show that the sintered sample contained only a $\alpha$-iron solid solution single phase.

We also microwave-sintered several powders of pure metals. Only one representative example is described here. Cobalt metal powder was pressed into pellets, and microwave sintered in pure $\mathrm{H}_{2}$ at 1 atmosphere pressure at various temperatures ranging from 900 to $1,200{ }^{\circ} \mathrm{C}$ for 10 minutes. The density reached $8.70 \mathrm{~g} \mathrm{~cm}^{-3}$ at $900{ }^{\circ} \mathrm{C}$ to $8.88 \mathrm{~g} \mathrm{~cm}^{-3}$ at $1,000-1,050^{\circ} \mathrm{C}$, and very near theoretical density of $8.89 \mathrm{~g} \mathrm{~cm}^{-3}$ at $1,100-1,200^{\circ} \mathrm{C}$.

These findings have implications for the field of powdered-metal technology. Metal powders are used in industry for a wide range of products and applications. Traditional powder metallurgy involves a process whereby a metal or alloy powder is compacted as a 'green' body and sintered to net shape at elevated temperatures. This process is not labour-intensive, but does consume considerable energy. It conserves materials, and produces high-quality components with reproducible properties. However, the need for materials of high integrity for advanced engineering applications requires newer technologies. The attainment of finer microstructures and near-theoretical densities in special powdered-metal components is still elusive and challenging. Increasing cost is also a concern. The microwave processing method reported here may offer fine microstructures and better properties in powdered-metal products at lower cost. The main reason why the microwave process yields better mechanical properties is two-fold, especially in the case of powdered metals: it produces finer grain size, and the shape of the porosity (if any) is different from that generated during conventional heating. In microwave-processed powdered-metal samples we observed round-edged porosities, producing higher ductility and toughness.

The implications for the fundamental science of microwavematerials interaction are less clear. What is certain from this work and that of Willert-Porada ${ }^{14}$ on ceramic sintering is that these interactions are more complex than hitherto suspected. The following factors, at least, contribute significantly to the total microwave heating of powdered metals (object shape and size are also wellknown to play a part, but have not been quantified in detail). First, the microwave field generated by a magnetron and the existence of an automatic cut-off mechanism to avoid burn-out due to reflected power. Second, the presence of $\mathrm{SiC}$ susceptor rods - taking up only a small fraction of the total space. Third, the existence of a cylindrical insulation package made of aluminosilicate fibres essentially transparent to $2.45-\mathrm{GHz}$ radiation at room temperature, surrounding an alumina tube. Last, the size and nature of the sample placed in the centre of the alumina tube (see Fig. 1).

How the microwave energy absorption is divided between the susceptors, insulation, and sample is a generic issue for all microwave processing, and we consider it in more detail in Supplementary Information. This analysis shows that there is no complete theory to explain even the simplest case of sintering of a ceramic. Furthermore, Cherradi et al. ${ }^{21}$ recently claimed that in most ceramics the dielectric loss mechanism was a minor contribution to the power absorbed compared to the induction losses caused by eddy currents. These authors also attribute the heating-they did no sintering-of metals also to eddy-current losses from the electric field. Their evidence, obtained using samples of different size and shape in different orientations, supports the role of such eddycurrent losses as a major contributor to the heating of metals. However, all their experiments were done in a single-mode cavity where the orientation of the electric and magnetic fields can be fixed. All our work was done in multimode cavities where the situation is much less determined; but the role of the electric field cannot be ignored.
Another possible significant contribution to the absorption of microwave power, on which much theoretical work has been done ${ }^{22}$, is multiple scattering in powdered assemblages; this is especially applicable to ceramics and higher microwave frequencies.

Received 9 October 1998; accepted 20 April 1999

1. Clark, D. \& Sutton, W. H. Microwave processing of materials. Annu. Rev. Mater. Sci. 26, 299-331 (1996)

2. Schiffman, R. F. Commercializing microwave systems: Paths to success or failure. Ceram. Trans. 59, 717 (1995).

Katz, J. D. Microwave sintering of ceramics. Annu. Rev. Mater. Sci. 22, 153-170 (1992).

4. Sutton, W. Microwave processing of ceramics: an overview. Mater. Res. Soc. Symp. Proc. 269, 3-19 (1992).

Sutton, W. Microwave processing of ceramic materials. Am. Ceram. Soc. Bull. 68, 376-386 (1989).

6. Fang, Y., Agrawal, D. K., Roy, D. M. \& Roy, R. Fabrication of transparent hydroxyapatite ceramics by microwave processing. Mater. Lett. 23, 147-151 (1995).

7. Agrawal, D. K., Fang, Y., Roy, D. M. \& Roy, R. Mater. Res. Soc. Symp. Proc. 269, 231-236 (1992).

8. Fang, Y., Agrawal, D. K., Roy, D. M. \& Roy, R. Fabrication of porous hydroxyapatite ceramics by microwave processing. J. Mater. Res. 7, 490-494 (1992).

9. Fang, Y., Roy, R., Agrawal, D. K. \& Roy, D. M. Transparent mullite ceramics from diphasic aerogels by microwave and conventional processing. Mater. Lett. 28, 11-15 (1996).

10. Fang, Y., Agrawal, D. K., Roy, D. M. \& Roy, R. Microwave sintering of calcium strontium zirconium phosphate ceramics. Ceram. Trans. 36, 109 (1993).

11. Fang, Y., Agrawal, D. K., Roy, D. \& Roy, R. Microwave sintering of hydroxyapatite-based composites. Ceram. Trans. 36, 397 (1993).

12. Roy, R., Agrawal, D., Cheng, J. P. \& Mathis, M. Microwave processing: triumph of applications-driven science in WC-composites and ferroic titanates. Ceram. Trans. 80, 3-26 (1997).

13. Cheng, J. P., Agrawal, D. K., Komarneni, S., Mathis, M. \& Roy, R. Microwave processing of WC-Co composites and ferroic titanates. Mater. Res. Innov. 1, 44-52 (1997).

14. Gerdes, T. \& Willert-Porada, M. Mater. Res. Soc. Symp. Proc. 347, 531-537 (1996).

15. Walkiewicz, J. W., Kazonich, G. \& McGill, S. L. Microwave heating characteristics of selected minerals and compounds. Min. Metall. Processing 5, 39-42 (1988).

16. Willert-Porada, M., Gerdes, T., Rodiger, K. \& Kolaska, H. Einsatz von Mikrowellen zum Sintern pulvermetallurgischer Prudukte. Metall 50, 744-752 (1996).

17. Nishitani, T. Method for sintering refractories and an apparatus therefor. US Patent No. 4147911 (1979)

18. Whittaker, A. G. \& Mingos, D. M. Microwave-assisted solid-state reactions involving metal powders. J. Chem. Soc. Dalton Trans. 2073-2079 (1995).

19. German, R. M. Sintering Theory and Practice (Wiley, New York, 1996).

20. Gedevanishvili, S., Agrawal, D. \& Roy, R. Microwave combustion synthesis and sintering of intermetallics and alloys. Mater. Sci. Lett. (submitted).

21. Cherradi, A., Desgardin, G., Provost, J. \& Raveau, B. Electric magnetic field contributions to the microwave sintering of ceramics. In Electroceramics IV Vol. II, (eds. Wasner, R., Hoffmann, S., Bonnenberg, D. \& Hoffmann, C.) 1219-1224 (RWTN, Aachen, 1994).

22. Shanker, B. \& Lakhtakia, A. Extended Maxwell Garnett formalism for composite adhesives for microwave-assisted adhesion of polymer surfaces. J. Compos. Mater. 27, 1203-1213 (1993).

Supplementary information is available on Nature's World-Wide Web site (http://www.nature.com) or as paper copy from the London editorial office of Nature.

Acknowledgements. We thank J. Kosco for providing powdered-metal components. We also thank the approximately 20 corporations that supported the early stages of this work, which is now supported by the Electric Power Research Institute, the Keystone Powder Metal Company and the Ben Franklin Technology Center.

Correspondence and requests for materials should be addressed to D.A. (e-mail: dxa4@psu.edu).

\section{Laboratory evolution of peroxide-mediated cytochrome P450 hydroxylation}

\author{
Hyun Joo, Zhanglin Lin \& Frances H. Arnold
}

Division of Chemistry and Chemical Engineering 210-41, California Institute of Technology, Pasadena, California 91125, USA

Enzyme-based chemical transformations typically proceed with high selectivity under mild conditions, and are becoming increasingly important in the pharmaceutical and chemical industries. Cytochrome P450 monooxygenases (P450s) constitute a large family ${ }^{1}$ of enzymes of particular interest in this regard. Their biological functions, such as detoxification of xenobiotics and steroidogenesis $^{2-5}$, are based on the ability to catalyse the insertion of oxygen into a wide variety of compounds $s^{6}$. Such a catalytic transformation might find technological applications in areas ranging from gene therapy and environmental remediation to 